\title{
The Role of Internet Marketing on E-Commerce
}

\author{
Hossein Niavand (Corresponding author) \\ Research Scholar, Department of studies in Business Administration (BIMS) \\ University Of Mysore, Mysore, India \\ E-mail: niavandd@gmail.com \\ Farzaneh Haghighat Nia \\ Research Scholar, Department of studies in Commerce \\ University of Mysore, Mysore, India \\ Dr. R. Mahesh \\ Chairman and Associate Professor, Department of studies in Business Administration \\ (BIMS) \\ University Of Mysore, Mysore, India
}

Received: April 7, 2018 Accepted: May 2, 2018 Published: May 27, 2018

doi:10.5296/bmh.v6i1.13204ＵRL: http://dx.doi.org/10.5296/bmh.v6i1.13204

\begin{abstract}
In this article, the examiner will consider the best Internet promoting routes for the achievement of a business. The principal goal of this article is only understanding the effect of the Internet on various showcasing regions, for example, item improvement and administration arrangement, advancement, valuing and conveyance channels. It is demonstrated that when makers associate straightforwardly with shoppers and abbreviate the circulation channels, wasteful aspects can be killed, item conveyance time can be diminished, and producers can construct the nearer association with purchasers. Purchasers utilize the Internet to lessen costs, discover items generally inaccessible, or increment their shopping accommodation. Online shoppers expect simple, justifiable, and secure requesting and instalment frameworks. Clients need confirmation that requests will be filled promptly. Internet business makes an incentive for clients from various perspectives. Clients are dealt with as a market of one. They can get a more prominent assortment of items, regularly at bringing down costs. The study suggests that businesses should pay special attention to the impacts of the Internet and its uses in marketing to be successful and profitable.
\end{abstract}

Keywords: Internet marketing, E-commerce, E-marketing, promotion. 


\section{Introduction}

Barely any things have significantly and quickly affected our lives and the way numerous organizations work more than the improvement of the Internet. The ways that some advertising exercises are performed have changed as organizations have swung to web-based business. The Internet gives chances to an association to upgrade its business in a financially savvy and down to earth way. That is, the Internet can be utilized to lead advertising research, achieve new markets, serve clients better, circulate items speedier, take care of client issues, and impart all the more proficiently with business accomplices. The advantage of Internet showcasing incorporates the enhanced stream of data, new items and client administrations, enhanced accessibility, enhanced market straightforwardness. To plan and actualize a fruitful e-showcasing program, various speculations, applications, and innovations must be deliberately broke down and caught on.

One of the most smoking subjects in business and the media today is an electronic trade. The Internet and its graphical interface, the World Wide Web (WWW), are key parts of an electronic business activity that is assuming a consistently expanding part later on of the worldwide commercial centre.

E-commerce has been defined as "any type of business exchange in which the gatherings connect electronically instead of by physical contact".

E-commerce and its application have turned out to be ordinary exchanges and different articles and writing have been composed in such manner. Access to the space of electronic world has moved toward becoming needs of the majority of all shapes and sizes open and private associations and accordingly; administrators have experienced new difficulties in this field.

Utilizing the web and related innovations to finish critical showcasing exercises is known as e-promoting or electronic advertising. The ways that some showcasing exercises are performed have changed as organizations have swung to web-based business. Be that as it may, the essential standards of promoting still apply. Web-based business organizations must comprehend advertising nuts and bolts and utilize them viable with a specific end goal to be effective and productive.

The omnipresent idea of the Internet and its worldwide access have made it a to a great degree successful method of correspondence amongst organizations and clients. The development of Internet innovation has tremendous potential as it diminishes the expenses of the item and administration conveyance and expands topographical limits in uniting purchasers and merchants. Additionally, universal interchanges created by the Internet are probably going to bring about more prominent levels of fulfilment amongst organizations and clients. The Internet gives chances to an association to improve its business in a financially savvy and viable way. That is, the Internet can be utilized to direct showcasing research, achieve new markets, serve clients better, disseminate items speedier, take care of client issues, and convey all the more proficiently with business accomplices. Quality advantages of web-based business utilize could incorporate the enhanced stream of data, new items and 
client administrations, enhanced accessibility, enhanced market straightforwardness and diminished blunders in data processing. The Internet is additionally a helpful device for social affair insight on clients, contenders, and potential markets, and in addition, imparting data about organizations as well as items.

\section{E-Commerce Customers}

Clients are the soul of a business. They choose whether to buy an organization's items or the results of a contender. They might be convinced to attempt an item once. On the off chance that fulfilled, they will probably buy from the organization once more. They may urge loved ones to purchase too. Organizations with fulfilled clients are probably going to be effective. Those that can't fulfil clients will soon fall flat.

A standout amongst the most vital undertakings of advertising is to distinguish imminent clients for an organization. The exercises expected to draw in clients incorporate advertising exploration and advancement that gets the consideration and enthusiasm of new prospects. Additionally imperative are a few kinds of motivating force to urge clients to make their first buy and follow-up exercises that guarantee consumer loyalty. Any worries the client has the item should be distinguished and settled. Organizations that have obviously distinguished their potential clients can focus their promoting assets on those prospects.

\subsection{Customers Characteristics}

There are sure kinds of buyers who are probably going to be web clients. They are individuals who are alright with innovation and development. Advancement is another and special item, process, or thought. A great many people are hesitant to take a stab at something that is absolutely new. Be that as it may, a little level of the populace (around two percent) is thought to be trailblazers. Trend-setters need to be the first to attempt new items. At the point when organizations started offering items on the web, trend-setters were their first clients.

Notwithstanding, if the business anticipates that shoppers will utilize the web to buy its items, showcasing endeavours ought to be coordinated toward pioneers and early adopters. Various profiles of Internet customers recommend their middle age to be in the range 30-35; for the most part single (59\%) and having a professional education (57\%). Each business approaches thousands and once in a while a huge number of customers. A business needs to build up a successful strategy for distinguishing those shoppers who are destined to buy. It should focus its advertising endeavours on pulling in and fulfilling those clients.

\section{Impacts of Internet Marketing}

In spite of the fact that there has been a pattern toward the new promoting approaches utilized as a part of internet business, it is not necessarily the case that conventional advertising ideas can't be connected. The regular four Ps of showcasing, item, value, advancement and place, are as applicable to online organizations as disconnected ones. Nonetheless, E-Commerce brings new issues that must be considered and may require a re-examining of the current promoting blend. E-Commerce advancements offer new item/benefit and new putting choices 
and in addition new valuing procedures. In any case, one of the greatest impacts has been on advancement.

\subsection{Crop}

The essential reason individuals buy from a business is straightforwardly identified with its items. Product qualities assume a noteworthy part in the fruitful showcasing of an item on the Internet. The type of a few items is altered with the utilization of the web. Electronic books, e-tickets, advanced photos, and online bill paying are cases of changes as conventional items. A few purchasers locate the new structures additionally fulfilling while others incline toward the items in their unique structures. There is an expansive scope of items showcased on the Internet that range from consumable products to strong merchandise. Administrations advertised on the Internet likewise go from online daily papers to extensive consultation.

\subsection{Digital Crop}

Computerized innovation has enabled organizations to build up another age of items. Organizations create and showcase an assortment of advanced items. Those items are intended for both business and shopper markets. Two classes of computerized items are substance and innovation. Computerized content comprises of data in the advanced configuration including video, sound, content, and illustrations. The substance is changed over to business and purchaser items, for example, daily papers, magazines, web-based recreations, photographs, illustrations, and recordings. Computerized innovation is the gear utilized by organizations and shoppers to create, store, disseminate, and utilize advanced substance. The innovation ranges from advanced video and sound hardware to cell phones, individual computerized aides (PDAs), and PC programming.

\subsection{Digital Services}

Similarly, as administrations are a noteworthy offering of conventional organizations, advanced administrations are similarly essential in web-based business. Advanced administrations are created and showcased to the two organizations and last buyers. Classifications of advanced administrations are business-bolster administrations, buyer administrations, and computerized correspondences administrations. Business-bolster administrations are the exercises that help organizations in creating and conveying advanced items and administrations. Business-bolster administrations incorporate website architecture, site facilitating and administration administrations, and computerized content generation, (for example, video, sound, and media improvement). Buyer administrations are the exercises that help purchaser access to and utilization of web assets and computerized data. Basic shopper administrations are web access suppliers (ISPs), data entryways, and media merchants, for example, computerized TV and radio stations. Computerized interchanges administrations give the administration of the innovation and methods that help business and shopper virtual correspondences. 


\subsection{Increase Crop for E-Commerce}

The improvement of PCs, the web, and computerized innovation has created open doors for new items. Many existing items can be showcased all the more broadly to planned clients. Furthermore, some new-to-the-world items have been produced because of late innovations. The web enables organizations to mass to tweak an extensive variety of items. Cases of items that are being exceptionally fabricated incorporate eyewear, attire, golf clubs, bikes, angling poles, and CDs. Littler organizations utilize customization to increase upper hand. Bigger organizations utilize customization to bring down expenses. Clients get and pay for just the highlights they require. Puma offers online customers the chance to alter a running shoe, customizing such highlights as the outsole, the measure of padding, and the width. The customized shoe costs about $\$ 10$ more than purchasing a practically identical-however not custom - shoe off the racks of the neighbourhood Puma retailer. Customers are additionally ready to customize men's and ladies' dress jeans and men's dress shirts at Landsend.com.

\section{Cost}

Cost is another boost that for most buyers highly affects the online purchase. Marketing estimating is still what it was, the value that clients will pay, in light of contemplations, for example, the organization, brand, notoriety, and item. The distinction that internet business makes is that evaluating and contender data is speedier and more straightforward, implying that market powers likewise tend to act quicker and maybe more proficiently. There is in this manner an inclination at costs to focalize at bring down levels.

Hypothesis improvement in re-valuing has to a great extent concentrated on value rivalry and value affectability online with respect to disconnected. The across the board conviction that pursuit costs are brought down online has started much enthusiasm among scientists in discovering methods for bringing down online value cognizance and making the separation. As Peterson et al. expressed Internet-related showcasing can bring about outrageous value rivalry when items or administrations are unequipped for critical separation.

\subsection{Cost-Based Strategies}

Organizations that attention on picking up a piece of the pie by offering at low costs or at costs that vary with advertise request are utilizing a valuing methodology. More noteworthy productivity enables a few organizations to offer at bringing down costs in light of lower general expenses. Cost investment funds result when a business does not require physical resources when fewer workers are required, and when innovation is utilized to reach and serve clients. Clients spare cash, time, and vitality when they can utilize the web to help in the pursuit and buy process.

Estimating choices are especially basic for the e-business as there is a client observation that costs ought to bring down online than something else. The web builds client transaction control. Clients can without much of a stretch find and look at costs among providers. Clients can utilize programming based hunt frameworks called keen shopping operators that arrival item and value data. My Simon utilizes canny shopping operators to give cost and item 
correlations. Keen shopping operators are helpful for looking at items that have comparative highlights and different sellers.

\subsection{Improvement}

Organizations utilize a limited time blend to achieve their destinations. A special blend incorporates publicizing, individual offering, deals advancements, and hypermedia. Today, most web-based business limited time crusades require a blend of customary strategies and hypermedia. Dependence on hypermedia alone may not enable an organization to achieve its objectives. Every component of the limited time blend has qualities for achieving particular correspondence objectives. An incorporated promoting correspondence technique unites different media to achieve wanted objectives. Hypermedia are most grounded in the regions of making interest and want, however, can likewise be utilized to encourage exercises, for example, selecting into a rundown or making a buy. Hypermedia upgrades the permeability of firms and makes new business openings. Hypermedia additionally spares cash and time and enables organizations to achieve new clients.

\section{Online Advertising}

Limited time position in a medium is known as publicizing. The web is the quickest developing promoting medium. It took just five years to achieve 50 million clients. To achieve this level of development, radio took 38 years, TV took 13 years, and the link took 10 years. In conventional showcasing, promoting was indifferent, one-way mass correspondence paid for by supports. Telemarketing and standard mail were endeavours to customize promotion keeping in mind the end goal to make it more compelling. These immediate showcasing approaches worked genuinely well yet were costly and moderate and occasionally really balanced intuitive. The Internet presents the idea of intelligent showcasing, which has empowered publicists to associate specifically with clients. It enables data to be gotten to without land area imperatives and offers the likelihood of conveying messages upgraded by shading, sound and liveliness impacts, and in addition two-way connections. The intuitive idea of the web encouraged client support and market exercises to a more noteworthy degree than conventional media. In intelligent advertising, a buyer can tap on an advertisement keeping in mind the end goal to get more data or send an email to make an inquiry. Next, to the two-way correspondence and email capacities given by the Internet, merchants additionally can target particular gatherings and people on which they need to spend their promoting dollars. Double tap is the chief organization around there. At last, the Internet empowers genuinely coordinated advertising. Online ads are adaptable; they can be redone and adjusted rapidly and effectively because of shopper profiles and changing business sector conditions.

\subsection{Mark Ads}

A flag is a reality show on a website page that is utilized for publicizing. Pennant publicizing is the most generally utilized type of promoting on the Internet. Banner advertisements are ordinarily little strip messages set in high-permeability regions of habitually went to Web locales. Banner promotions act like position advertisements in print media. To get a watcher's 
attention, standard promotions are currently utilizing movement, java programming, and interactive media. Standard advertisements are valuable in making consciousness of items and in imparting data about them.

\section{Distribution Place}

Distribution is a critical piece of any promoting exchange. It more often than not includes a few organizations. It might take numerous days or long stretches of various exercises. Dispersion is costly. It can represent 50 percent or to a greater extent an item's last cost. Circulation exercises don't vanish when a business moves to an online business methodology.

Conveyance is an indispensable choice region for the e-business for three reasons. Initially, moderately little nearby organizations can extend their market and even fare. Second, numerous e-organizations intend to pick up the upper hand by utilizing e-frameworks to de-layer the dispersion chain. For instance, Dell supplies clients specifically, instead of through merchants, wholesalers or retailers. Third, dissemination is a region where some re-organizations have been severally reprimanded for neglecting to convey client benefit.

\subsection{E-Commerce Distribution}

Showcasing divert middle people were in the beginning of electronic business considered to include just cost and restricted esteem, where upstream members seeking after electronic trade systems debilitated such mediators by endeavouring to sidestep them. Using the Internet, producers can offer straightforwardly to clients and give client bolster on the web. In this sense, the conventional middle people are killed, or disintermediated. Disintermediation alludes to the evacuation of associations or business process layers in charge of certain mediator ventures in a given store network. In a few nations, for example, Japan, one may discover wasteful circulation systems with upwards of 10 layers of delegates. These additional layers can include as much as a 500 percent mark-up to the makers' costs.

The best classifications of things sold by bigger firms on the Internet incorporate PC equipment and programming, carrier and lodging reservations, money related administrations, collectibles, books, CDs and blessing things. The best and benefit making vast locales incorporate Dell, Expedia, E*TRADE, e-Bay, Yahoo! also, Amazon. However not all products and enterprises are suited to coordinate deal over the Internet. In numerous segments, the Web speaks to another channel or wellspring of data supporting deals by different means. Scarcely any high-esteem things, for example, autos are exchanged over the Internet, yet many destinations give data important to auto buyers. Also, there are many locales for land, however few direct buyers of homes over the Internet.

Jupiter communications examinations demonstrate that the biggest businesses associated with internet shopping in the USA were, in diminishing request; travel, PC equipment, basic needs, endowments/blooms, books, PC programming, tickets, music, and garments. At the point when makers associate specifically with customers and abbreviate the appropriation chain, wasteful aspects can be disposed of, item conveyance time can be diminished, and producers can fabricate a nearer association with shoppers. At the point when the Internet can fill in as a trade for the middle person in overseeing data spill out of purchasers back to the makers, the 
request can be measured all the more precisely and requests can be put rapidly. At the point when the Internet likewise gives the chance to makers to specifically contact shoppers to give item data or data about requests, the requirement for the conventional go-betweens is lessened or dispensed with. Dell Computer has set up itself as one of the world's best e-posteriors by productively offering its PCs specifically to a large number of purchases over the Internet.

\subsection{Comparing Traditional and E-Commerce Distribution}

While past channel looks into has concentrated basically on arranging satisfaction (i.e., physical appropriation) through the retail channel, it is presently important to recognize on the web and disconnected channels and between the channels' part for arranging acquirement and request satisfaction. For items disseminated through the Internet, the channel for arranging satisfaction might be short as with coordinate conveyance. Be that as it may, the channel for arranging acquisition is regularly long with delegates, for example, Internet specialist organizations, web indexes, and infobots.

At the point when customers wind up plainly general web buyers, their viewpoints with respect to conveyance regularly change. Buyers utilize the web to decrease costs, discover items generally inaccessible or increment their shopping comfort. Web clients commonly expect benefit 24 hours every day, seven days seven days. Brisk access to client bolster data with respect to items, costs, and sending choices is normal. Since the speed of the web is relatively quick, clients have a tendency to expect the speed of dissemination to be quick too. Clients might be unwilling to sit tight days or weeks for item conveyance. Online customers expect simple, justifiable, and secure requesting and instalment frameworks. Clients need affirmation that requests will be filled promptly. They need a simple, minimal effort approach to restore a buy in the event that it doesn't address their issues.

\section{Value in an E-Commerce}

Buyers settle on choices about the esteem in view of how they will utilize accessible assets to fulfil their requirements and needs. At its most fundamental, the esteem is the advantages that clients get given the expenses (in cash, time, and vitality). Value appears to affect a customer's utilization conduct, evaluating, benefit settling on and other key choices of the firm. It is utilized to increase upper hand and to make devotion, fulfilment and repurchase conduct. Along these lines, esteem is a mind-boggling idea, which is incredibly influenced by individual and relevant angles. Esteem is a critical method for increasing upper hand. In this manner, it is huge for administrators to comprehend what esteem are, the way it is made and how it could be included.

Web-based business makes an incentive for clients from multiple points of view. Clients are dealt with as a "market of one." Businesses make an incentive by giving quality merchandise and enterprises at adequate costs. Administration organizations are upgrading how they convey their administration. Clients can get a more prominent assortment of items, frequently at bring down costs. The most vital incentive for some, online customers is the comfort. One examination found that customers spared just about 64 hours for every year by shopping on 
the web. The e-business esteem for the client comprises of four factors: administration, cost, and quality and satisfaction time.

\section{Euphoria}

The web gives numerous chances to organizations to increment monetary utility and, accordingly, consumer loyalty. The most evident types of enhanced utility are time and place. Data can be gotten to and items can be acquired whenever of the day or night. Obtaining can be finished from the shopper's home. Amazon.com is scoring fulfilment levels at no other time found in an administration industry. Amazon.com is applying its esteem creation process utilized with books to numerous different items. Amazon.com web based business applications set esteem levels so high that client desires are expanding for Amazon.com as well as for all organizations.

The fundamental innovations that online business organizations use to include esteem are the web and databases. The web enables access to web-based business correspondence stages. Databases enable items to be looked and seen, inquiries to be replied, and items to be requested, all in a quick and advantageous time period. At one time, online-just organizations were the main organizations utilizing these advancements. Today, customary organizations are adding web-based business techniques to their showcasing blends. At the point when web-based business is joined with famous brand names and abnormal amounts of administration, conventional organizations accomplish aggressive advantages.

\section{Conclusion}

This paper depicts the ways that some promoting exercises are executed as organizations have swung to online business. Discoveries demonstrate that the development of Internet innovation has tremendous potential for organizations. There are sure sorts of purchasers who are probably going to be web clients. They are individuals who are OK with innovation and advancement. In the event that the business anticipates that buyers will utilize the web to buy its items, advertising endeavours ought to be coordinated toward pioneers and early adopters.

The Internet brings new issues that must be considered and may require a reconsidering of the current promoting blend. The web enables organizations to mass to tweak an extensive variety of items. The Internet makes estimating and contender data quicker and more straightforward, implying that market powers likewise tend to act speedier and maybe more proficiently. The Internet presents the idea of intelligent showcasing, which has empowered promoters to cooperate specifically with clients. It enables data to be gotten to without land area imperatives and offers the likelihood of conveying messages upgraded by shading, sound and movement impacts, and also two-way cooperation's. Utilizing the Internet, makers can offer specifically to clients and give client bolster on the web. In this sense, the conventional middle people are dispensed with, or disintermediated.

It is critical for an administrator to comprehend what esteem is the manner in which it is made and how it could be included. The web gives numerous chances to organizations to increment monetary utility and, in this manner, consumer loyalty. 


\section{Ml Macrothink}

Business and Management Horizons

ISSN 2326-0297

2018, Vol. 6, No. 1

\section{References}

Aldin, N., \& Stahre, F. (2003). Electronic commerce, marketing channels and logistics platforms - a wholesaler perspective. European Journal of Operational Research, 144(2), 270-279. http://doi.org/ 10.1016/S0377-2217(02)00393-4

Avlonitis, G. J., \& Karayanni, D. A. (2000). The impact of internet use on business-to-business marketing: examples from American and European companies. Industrial Marketing Management, 29(5), 441-459.

Boone, L. E., \& Kurtz, D. L. (2006). Principles of marketing. South-Western.

Burrow, J. L., Kleindl, B., \& Everard, K. E. (2007). Business principles and management. Cengage Learning.

Chen, S. (2005). Strategic management of e-business.

Drew, S. (2003). Strategic uses of e-commerce by SMEs in the east of England. European Management Journal, 21(1), 79-88. https://doi.org/10.1016/S0263-2373(02)00148-2

Fagerstrøm, A., \& Ghinea, G. (2011). On the motivating impact of price and online recommendations at the point of online purchase. International Journal of Information Management, 31(2), 103-110.

Honeycutt, E. D., Flaherty, T. B., \& Benassi, K. (1998). Marketing industrial products on the $\begin{array}{llll}\text { Internet. Industrial } \quad \text { Marketing } \quad \text { Management, } & \text { 27(1), }\end{array}$ http://doi.org/10.1016/S0019-8501(97)00038-2

Kiang, M. Y., Raghu, T. S., \& Shang, K. H. M. (2000). Marketing on the Internet-who can benefit from an online marketing approach?. Decision Support Systems, 27(4), 383-393.

Lewis, R., \& Cockrill, A. (2002). Going global-remaining local: The impact of e-commerce on small retail firms in Wales. International Journal of Information Management, 22(3), 195-209.

Reijonen, H., Buratti, A., Hirvonen, S., \& Laukkanen, T. (2015, November). An examination of strategic orientation profiles of low-and high-performing international SMEs. Australian \& New Zealand marketing academy conference. https://erepo.uef.fi/handle/123456789/114

Samiee, S. (2008). Global marketing effectiveness via alliances and electronic commerce in business-to-business markets. Industrial Marketing Management, 37(1), 3-8.

Teo, T. S., \& Yu, Y. (2005). Online buying behaviour: a transaction cost economics perspective. Omega, 33(5), 451-465.

Turban, E., Sharda, R., Aronson, J. E., \& King, D. (2008). Business intelligence: A managerial approach (pp. 58-59). Upper Saddle River, NJ: Pearson Prentice Hall. 


\section{Macrothink}

\section{Copyrights}

Copyright for this article is retained by the author(s), with first publication rights granted to the journal.

This is an open-access article distributed under the terms and conditions of the Creative Commons Attribution license (http://creativecommons.org/licenses/by/4.0/). 